\title{
Commentary: Left ventricular size and left ventricular assist device support outcomes: Bigger is better?
}

\author{
Francis D. Pagani, MD, PhD
}

\author{
From the Department of Cardiac Surgery, University of Michigan, Ann Arbor, Mich. \\ Disclosures: Author has nothing to disclose with regard to commercial support. \\ Received for publication Jan 19, 2019; accepted for publication Jan 21, 2019; available ahead of print Feb 21, \\ 2019. \\ Address for reprints: Francis D. Pagani, MD, PhD, Department of Cardiac Surgery, University of Michigan Health \\ System, 1500 East Medical Center Drive, Ann Arbor, MI 48109 (E-mail: fpagani@umich.edu) \\ J Thorac Cardiovasc Surg 2019;157:2313-4 \\ $0022-5223 / \$ 36.00$ \\ Copyright (C) 2019 by The American Association for Thoracic Surgery \\ https://doi.org/10.1016/j.jtcvs.2019.01.076
}

Durable left ventricular assist device (LVAD) therapy affords patients significant improvements in survival, functional capacity, and quality of life. Despite these benefits, LVAD therapy is associated with a number of important adverse events, most notably stroke and device malfunction secondary to device thrombosis. However, as durable LVAD therapy has matured over the past decade, our understanding of patient characteristics and nonpatient factors that contribute to a higher risk of stroke and pump thrombosis has improved, permitting providers greater accuracy in assessing individual patient operative risk and using risk mitigation strategies to prevent these complications.

In this issue of the Journal, Kawabori and colleagues ${ }^{1}$ report on a single-center, retrospective, observational study of durable LVAD outcomes stratified by left ventricular (LV) dimension and demonstrated that a small left ventricular end-diastolic dimension (LVEDD) was an independent predictor of mortality (hazard ratio, 1.49; $P=$ .02 ) and that postoperative stroke was more common in patients with an LVEDD less than $6.0 \mathrm{~cm}$ compared with patients with an LVEDD $6.0 \mathrm{~cm}$ or greater $(P<.01)$. The findings by Kawabori and colleagues ${ }^{1}$ are important and support previous findings from the Interagency Registry for Mechanically Assisted Circulatory Support and others of the importance of LV size on LVAD outcomes. ${ }^{2-4}$ Intuitively, the smaller ventricle possesses technical challenges with respect to alignment of the inflow cannula, and lower flows in smaller patients with small chambers may be beyond the design capabilities of some technology, leading to a greater risk of pump thrombosis. There are a number of limitations in the study by Kawabori and colleagues. ${ }^{1}$ First, to what extent poor surgical technique with misalignment of the inflow cannula or low-flow conditions contributed to stroke or pump thrombosis was not elucidated by the data in the study by Kawabori and colleagues. ${ }^{1}$ Second, only $91(23 \%)$ of the overall group of 393 patients had an LVEDD less than $6.0 \mathrm{~cm}$, and of that number, only 33 (8.4\% of the total group) had an LVEDD less than $5.5 \mathrm{~cm}$. Thus, the observations were

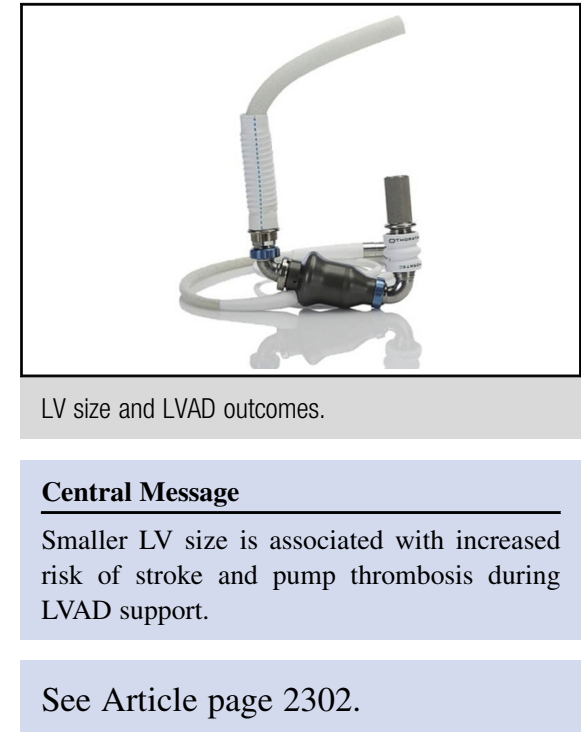

based on a small number of patients, largely with a preoperative LVEDD between 5.5 and $6.0 \mathrm{~cm}$. Third, the study observations with respect to LV dimensions that are associated with increased risk were demonstrated in a population of patients receiving the HeartMate II device (Abbott Laboratories, Chicago, Ill). It is likely that a specific range of LV dimensions that may be associated with increased risk of stroke and pump thrombosis may be device specific. More recent continuous-flow rotary pump technology using total magnetic levitation of the impeller (ie, HeartMate 3; Abbott Laboratories) may be more resilient to lower flow conditions, as evidenced by a significantly lower rate of pump thrombosis and lower rate of stroke compared with the HeartMate II device. ${ }^{5}$ Thus, a comparative study across several devices would have been more informative of the relative risk that is present for each device with a small ventricle.

The study by Kawabori and colleagues ${ }^{1}$ highlights the need for closer attention to surgical technique with smaller ventricles and the need for newer technology that can accommodate smaller ventricular sizes over a wider range of pump flows.

\section{References}

1. Kawabori M, Kurihara C, Conyer R, Sugiura T, Critsinelis BS, Lee VV, et al. A left ventricular end-diastolic dimension less than $6.0 \mathrm{~cm}$ is associated with mortality after implantation of an axial-flow pump. J Thorac Cardiovasc Surg. 2019;157: 2302-10. 
2. Shah P, Birk S, Maltais S, Stulak J, Elmi A, Pagani FD, et al. Left ventricular assist device outcomes based on flow configuration and pre-operative left ventricular dimension: an interagency registry for mechanically assisted circulatory support analysis. J Heart Lung Transplant. 2017;36:640-9.

3. Patel SR, Saeed O, Naftel D, Myers S, Kirklin J, Jorde UP, et al. Outcomes of restrictive and hypertrophic cardiomyopathies after LVAD: an INTERMACS analysis. J Card Fail. 2017;23:859-67.
4. Topilsky Y, Oh JK, Shah DK, Boilson BA, Schirger JA, Kushwaha SS, et al Echocardiographic predictors of adverse outcomes after continuous left ventricular assist device implantation. JACC Cardiovasc Imaging. 2011;4: 211-22.

5. Mehra MR, Goldstein DJ, Uriel N, Cleveland JC Jr, Yuzefpolskaya M, Salerno C, et al. Two-year outcomes with a magnetically levitated cardiac pump in heart failure. N Engl J Med. 2018;378:1386-95. 